\title{
Evaluation of Global Solar Radiation Models for Inclined Surfaces
}

\author{
M. Mesri \\ Laboratoire des Semi-Conducteurs et Matériaux Fonctionnels, \\ Amar Telidji University \\ BP 37G, Ghardaïa Road-Laghouat, Algeria
}

\author{
L. Chaib \\ LACoSERE Laboratory, Amar Telidji University of Laghouat \\ BP 37G, Ghardaïa Road-Laghouat, Algeria
}

\begin{abstract}
Predicting the efficiency of solar photovoltaic and solar thermal systems needs global solar radiation data and its estimation models. Furthermore, daily global solar radiation models are required for engineering design and planning projects. In this paper, five daily global solar radiation models for tilted surfaces are compared and analyzed. They are namely: Jordan, Hay, Baltas, Perez and Klucher models. In order to assess the applicability and accuracy of the models proposed in this study, the radiometric and geographical data are used. Comparative analyses are established according to 50 years meteorological data. They are supplied by the National Office of Meteorology -NOM-, (Dar El Beida, Algeria, $3.21^{\circ} \mathrm{E}, \mathbf{3 6 . 6 8}^{\circ} \mathrm{N}$ ) and the Unit for Applied Research in Renewable Energy -UARRE- (Ghardaïa, Algeria, $3.80{ }^{\circ} \mathrm{E}, 32.4^{\circ} \mathrm{N}$ ). This latest selected station is quite interesting as it is situated a hundred kilometers far from the famous hybrid (solar, gas) station of Hassi R'Mel). Moreover, it provides reliable data. Finally, we find it necessary to mention that the obtained results show that the selected models have been able to estimate global solar radiation accurately so that complex equation types could not obviously improve the precision. The adequacy of a model is established on the basis of various usual errors such as the root mean square error (RMSE), the mean bias error (MBE) and the mean percentage error (MPE). Results are with attractive margins of error and in accordance with experimental measurements. These models take into account the type of contributions to diffuse radiation, that is to say, the isotropic and anisotropic sky.
\end{abstract}

Keywords-daily global solar radiation; illumination; meteorological data; isotropy of sky; anisotropy of sky; models for inclined surfaces

\section{INTRODUCTION}

Using solar energy in various technologies and domestic becomes more and more popular. The efficiency measurement and modeling of solar energy, using technological systems is becoming a very important issue. In Northern countries this importance is even higher. For efficient solar energy use the awareness of solar radiation in a particular place at a particular time is a key issue.

\author{
A. Choucha \\ LACoSERE Laboratory, Amar Telidji University of Laghouat \\ BP 37G, Ghardaïa Road-Laghouat, Algeria
}

In Algeria, solar irradiance is not being measured by all hydro meteorological stations while other meteorological parameters (e.g. sunshine duration, temperature, humidity and rainfall) are recorded more comprehensive and detailed. This leads that reliable solar radiation simulation program becomes even more challenging; researches on solar radiation and the atmosphere become more and more important in recent years. Hence, several models have been suggested in previous works [1-6]. These models vary from the simple empirical relationships to the most complex and sophisticated computer codes. Angstrom [7] proposed first, a theoretical model for estimating global solar radiation based on sunshine duration. However, models of estimation based on the co-relationship of available parameters such as atmospheric temperature, relative humidity, extra terrestrial radiation have been developed recently [8-16]. The main objective of this work is to compare five models namely: Liu \& Jordan, Hay, Baltas, Klucher and Perez, which deal with some radiometric parameters and other geographic coordinates such as latitude, longitude and altitude of the site under study, for estimating the daily global solar radiation on an inclined surface. The simulation results widely demonstrate the performance and effectiveness of the proposed models as compared to these obtained with measured values.

\section{METHODOLOGY}

First, we have established a literature review through which we have chosen the models proposed in the literature to recover the daily global radiation on a tilt surface and a suitable orientation. Their efficiency has been assessed through comparisons with ground measurements based experimental data. These are performed by the NOM and the UARRE, a radiometric station installed at the Research Unit of Ghardaïa.

\section{A. Model of Lui and Jordan}

In this model [17] the global illumination on a plane inclined at an angle $\beta$ ' is calculated by the following equation:

$$
G_{i}=I\left(\frac{\cos \theta_{i}}{\cos \theta_{z}}\right)+D\left(\frac{1+\cos \beta^{\prime}}{2}\right)+G \cdot \rho\left(\frac{1-\cos \beta^{\prime}}{2}\right)
$$




\section{B. Model of Temps and Coulson}

Recall that the illumination of the diffuse radiation is that we have received from all the sky except for the one that comes to us from the solar disk.

Given the complexity distribution and variety of this component, which is of course due to diffusion by the various constituents of the atmosphere, a common assumption has been made by various scientists to quantify this component.

It is assumed that the distribution of the latter is an isotropic distribution. Under this hypothesis, Liu and Jordan have given expression to refer the diffuse component available for a horizontal surface on a plane with a $\beta$ angle. This relationship is given by:

$$
\operatorname{Din}=D\left(\frac{1+\cos (\beta)}{2}\right)
$$

Furthermore, it was shown that the distribution of solar radiation in the sky is anisotropic and the hypothesis that considers the anisotropic distribution of diffuse radiation leads to considerable errors in the reconstruction of the diffuse component on an incline plane.

Temps and Coulson [18] have developed a new model where they consider that the distribution of the illumination of the diffuse radiation follows an anisotropic distribution. In their relationship, a correction was made to account for this phenomenon. They have proposed the following relationship:

$$
D(\beta, \gamma)=D_{h}\left(\frac{1+\cos (\beta)}{2}\right)\left[1+\sin ^{3}\left(\frac{\beta}{2}\right)\right] \cdot\left[1+\cos ^{2}\left(\theta_{i}\right) \sin ^{3}(90-h)\right]^{(3)}
$$

Where we find:

Isotropic part characterized by the first form factor, the second form factor that represents the effect of the horizon during periods when the state of the sky is clear and the third factor that characterizes the amount of the lighting of the diffuse solar radiation coming from the area circum.

Thus the amount of energy collected by any plane sensor which is used for either thermodynamic or photovoltaic conversion purposes depends both on the thermomechanical or electromechanical characteristics as well as the geometric configurations from where we have the inclination and orientation of the considered sensor.

\section{Model of Hay}

The model proposed by Hay [19] is written as follows:

$$
G_{i}=I\left(\frac{\cos \theta_{i}}{\cos \theta_{z}}\right)+D\left(\frac{I}{I_{o}}\left(\frac{\cos \theta_{i}}{\cos \theta_{z}}\right)\right)+D \cdot 0 \cdot 5 \cdot\left(1+\cos \beta^{\prime}\right)\left(G-\frac{I}{I_{o}}\right)+G \cdot \rho\left(\frac{1-\cos \beta^{\prime}}{2}\right)
$$

\section{Del of Kluche}

Klucher [20] has modified the model of Temps and Coulson, in this case:

$$
\begin{gathered}
G_{i}=I\left(\frac{\cos \theta_{i}}{\cos \theta_{2}}\right)+D\left(\frac{1+\cos \theta_{i}}{2}\right)+\left(1+f \cdot\left(\sin \left(\frac{\beta^{\prime}}{2}\right)\right)^{2}\right) \cdot\left(1+f \cdot\left(\cos \left(\frac{\beta^{\prime}}{2}\right)\right)^{2}\right) \cdot\left(\sin \left(\frac{\beta^{\prime}}{2}\right)\right)^{2}+G \cdot \rho\left(\frac{1-\cos \beta^{\prime}}{2}\right) \\
f=1-\left(\frac{D}{G}\right)^{2}
\end{gathered}
$$

\section{E. Model of Perez}

This model [21] is given by the following expression:

$$
G_{i}=I\left(\frac{\cos \theta_{i}}{\cos \theta_{z}}\right)+D\left(1-f_{1}\right)\left(\frac{1+\cos \beta^{\prime}}{2}\right)+D \cdot f_{1} \cdot \frac{a}{b}+D \cdot f_{2} \cdot \sin \beta^{\prime}+G \cdot \rho\left(\frac{1-\cos \beta^{\prime}}{2}\right)(7)
$$

With: $f_{1}, f_{2}, a, b$ and $\varepsilon$ are respectively factors given by:

$$
\begin{gathered}
\Delta=\frac{D}{I_{o}} \\
f_{1}=\max \left[0,\left(f_{21}+f_{22} \cdot \Delta+\frac{\pi \cdot \theta_{z}}{180} \cdot f_{13}\right]\right. \\
f_{2}=\left(f_{21}+f_{22} \cdot \Delta+f 23 \cdot \theta_{z}\right)
\end{gathered}
$$$$
f_{11}, f_{12}, f_{13}, f_{21}, f_{22} \text { and } f_{23} \text { are numerically }
$$
calculated based on the values of the index $\mathcal{E}$ [22]

$$
\begin{gathered}
\varepsilon=\frac{\frac{D+\left(\frac{1}{\cos \theta_{z}}\right)}{D}+5 \cdot 535 \cdot\left(10^{-6}\right) \cdot \theta_{z}{ }^{3}}{1+5 \cdot 35 \cdot\left(10^{-6}\right) \cdot \theta_{z}{ }^{3}} \\
a=\max \left[0, \cos \theta_{\mathrm{i}}\right] \\
b=\max \left[\cos 85, \cos \theta_{\mathrm{z}}\right]
\end{gathered}
$$

\section{F. Model of Baltas}

Another relationship that expresses the distribution of the Global radiation and which takes into account the anisotropy of the sky is the relationship Baltas [23] which is given by the following law:

$$
\begin{gathered}
\left.G_{i}=I\left(\frac{\cos \theta_{i}}{\cos \theta_{z}}\right)+D\left(\frac{1+\cos \beta^{\prime}}{2}\right)+\left(1+F \cdot\left(\sin \left(\frac{\beta^{\prime}}{2}\right)\right)\right)^{3}\right) \cdot\left(\frac{1+F \cdot\left(\cos \theta_{i}\right)^{2}\left(\sin \theta_{z}\right)^{3}}{1+F \cdot\left(\cos \theta_{z}\right)^{2}\left(\sin \theta_{z}\right)^{3}}\right)+ \\
\text { G. }\left(\frac{1-\cos \beta^{\prime}}{2}\right) \\
F=1-\frac{D}{G}
\end{gathered}
$$

In all which preceded,

$I, D$ and $G$ are respectively the direct components, diffuse and global on horizontal plane.

$\theta_{i}$ is the angle of incidence.
$\gamma$ is the elevation of the plane. 
$\beta$ is the inclination of the plane.

$\beta^{\prime}$ is the optimal tilt angle.

$\theta_{z}$ is the zenith angle.

\section{QUALITY CRITERION}

The performance and accuracy of proposed models in predicting hourly global solar radiation was estimated on the basis of the following error calculation tests which are the root mean square error (RMSE), the mean bias error (MBE) and the mean percentage error (MPE). These functions are provided in Eqs. 16-19 where $\mathrm{Vm}$ is the measured value when $\mathrm{Vc}$ is the calculated value, $\mathrm{EK}$ is the relative error and $\mathrm{N}=24$. These error indices are defined as:

$$
\begin{aligned}
& R M S E=\left[\frac{1}{N} \sum_{K=1}^{N}\left(V_{m}(K)-V_{c}(K)\right)^{2}\right] \\
& \operatorname{MPE}(\%)=\frac{1}{N} \sum_{K=1}^{N} E_{K} \\
& E_{K}(\%)=A b s\left(\frac{V_{m}(K)-V_{c}(K)}{V_{m}(K)}\right) .100 \\
& \operatorname{MBE}(\%)=\frac{1}{N} \sum_{K=1}^{N}\left(V_{m}(K)-V_{c}(K)\right)
\end{aligned}
$$

\section{RESULTS AND DISCUSSIONS}

In this article, we have evaluated the performance of different models for the estimation of global solar radiation on inclined surface. The latitude of the site is chosen as tilt angle. In order to find the best suitable model, the study is expanded to comparison between the proposed models and the measured values. For approaching to real values, we have taken the experimental data consisting of measurements for typical days according to each season during consecutive 50 years up to the year 2008 .
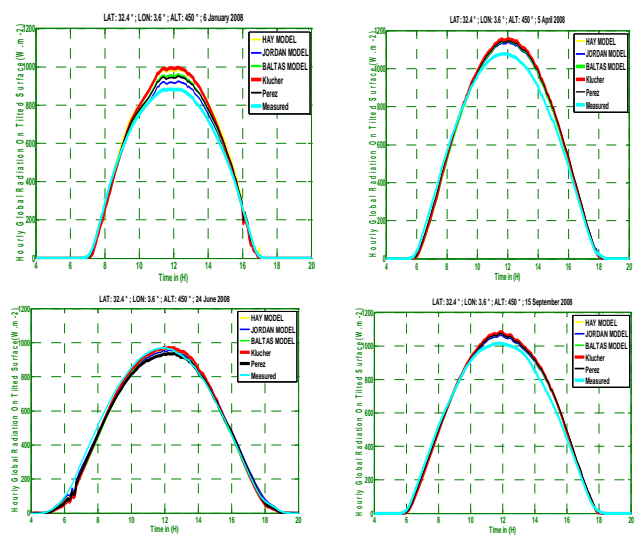

FIGURE I. GLOBAL SOLAR RADIATION MEASURED AND CALCULATED BY DIFFERENT MODELS

Figs. 1-4 show that the obtained results greatly indicate superior agreement between the measured and estimated values of daily global solar radiation. Table 1 reports main errors calculations, which clearly proves the effectiveness and performance of the five proposed selected models.

It can be concluded that the simulation models for the case of inclined surfaces give more meaningful results [24-25]. The requirements for these simulation models involve some measured parameters. The precision with which these parameters are determined affect the performance of these

\begin{tabular}{|c|c|c|c|c|c|c|}
\hline Model & \multirow{2}{*}{$\begin{array}{l}\text { Type of } \\
\text { error }\end{array}$} & \multirow[t]{2}{*}{ Jordan } & \multirow[t]{2}{*}{ Hay } & \multirow[t]{2}{*}{ Baltas } & \multirow[t]{2}{*}{ Perez } & \multirow[t]{2}{*}{ Kluche } \\
\hline Day & & & & & & \\
\hline \multirow{3}{*}{06 January } & MPE & 5.2103 & 8.6491 & 7.0011 & 5.8834 & 7.8842 \\
\hline & RMSE & 19.5912 & 47.0691 & 32.3209 & 30.4713 & 46.3729 \\
\hline & MBE & 5.1968 & 24.7212 & 10.7012 & 14.9005 & 18.9350 \\
\hline \multirow[t]{3}{*}{05 April } & MPE & 7.3744 & 8.1112 & 8.1986 & 8.1900 & 8.5022 \\
\hline & RMSE & 35.0953 & 41.1346 & 39.2262 & 39.4751 & 43.8436 \\
\hline & MBE & 14.7430 & 19.2890 & 13.7243 & 18.3093 & 18.2054 \\
\hline \multirow{3}{*}{24 June } & MPE & 6.2807 & 5.8167 & 9.8650 & 7.8332 & 9.4817 \\
\hline & RMSE & 18.0440 & 18.9275 & 27.1032 & 22.7169 & 24.3788 \\
\hline & MBE & -1.3572 & -4.0296 & -9.8921 & -9.6416 & -4.0881 \\
\hline \multirow{3}{*}{$\begin{array}{l}15 \\
\text { September }\end{array}$} & MPE & 6.4785 & 7.0555 & 7.2073 & 7.5179 & 7.5536 \\
\hline & RMSE & 27.7540 & 33.2443 & 30.9376 & 32.2481 & 35.3975 \\
\hline & MBE & 10.5642 & 15.3120 & 10.4229 & 14.8783 & 14.3684 \\
\hline
\end{tabular}
models and the quality of the results.

TABLE I. AVERAGE RELATIVE ERROR OF THE MEASURED AND CALCULATED VALUES OF GLOBAL RADIATION.

$\mathrm{V}$

CONCLUSION

The wide range of applications requiring the solar radiation data, the direct measurement of the solar energy is not widely 
available. This has made the use of digital techniques once more, an alternative key. With these indirect techniques, some observed data are mathematically exploited in order to estimate the amount of global solar radiation reaching the earth. In the present work, we have established a literature review through which we selected the models that are proposed in the literature to reconstruct the global radiation on a tilt surface and a given orientation. Based on the comparative analysis of global solar radiation models with 50 years measured data, all the methods presented in this study are able to predict global radiation within little limits for the chosen station.

Thus the selected models seem to give very satisfactory estimates. Consequently, they are of particular interest to manage the rational exploitation of solar radiation in Algeria and similar climatic regions. The independent variables are chosen taking into account their ease of being measured with inexpensive equipment [26]. Indeed, the number of independent variables directly affects the accuracy of predictions, and could represent a line of research in our laboratory.

\section{ACKNOWLEDGMENTS}

This study is mainly funded by 'Laboratoire des Semi-Conducteurs et Matériaux Fonctionnels, Algeria'. The authors wish to thank warmly the Algerian Office of Meteorology as well as the Unit of research for Renewable Energy for their help in the collection of experimental data.

\section{REFERENCES}

[1] R.K. Swartman, O. Ogunlade, "Solar radiation estimates from common parameters Array', Solar Energy, December 11-3 1967, pp.170-172.

[2] B. Leckner, "The spectral distribution of solar radiation at the earth's surfaces, Element of model", Solar energy 20-2, 1978, pp. 143-150.

[3] G. Lewis, "Estimates of irradiance over Zimbabwe", Solar Energy 31-6, 1983, pp. 609-12.

[4] I.G.D. Ra, "Solar energy utilization", Naisarak, Delhi: Khanna Publisher; 1984. p. 24-5.

[5] J.O. Ojosu, L.K. Komolafe, "Models for estimating solar radiation availability in South Western Nigeria", Nigerian Journal of Solar Energy 16, 1987, pp. 69-77.

[6] K.K. Gopinathau, "Solar sky radiation estimation techniques", Solar Energy, July 49-1, 1992, pp. 9-11,.

[7] A. Angstrom, "Solar and terrestrial radiation", Quarterly Journal of the Royal Meteorological Society, April 50-210, 1924, pp. 121-125.

[8] A.A. Trabea, M.A MosalamShaltout, "Correlation of global solar radiation with meteorological parameters over Egypt", Renewable Energy October, 21-2, 2000, pp. 297-308.

[9] R. Chen, K.Ersi, J. Yang, S. Lu, W. Zhao, "Validation of five global radiation models with measured daily data in China", Energy Conversion and Management July 45-11, 2004, pp. 1759-1769.

[10] M. El-Metwally, "Simple new methods to estimate global solar radiation on meteorological data in Egypt", Atmospheric Research, January 69-3, 2004, pp. 217-239.

[11] K.R. Genwa, C.P. Sagar, "efficiency Energy. Solar energy conversion and storage in photogalvanic cell", Energy Convers Manage, February 2013, pp.121-126.

[12] E. Kabalci, "Design and analysis of a hybrid renewable energy plant with solar and wind power", Energy Convers Manage, August 72, 2013, pp. $51-59$.
[13] A. Fudholi, K. Sopian, M.Y. Othman, M.H. Ruslan, B. Bakhtyar, "Energy analysis and improvement potential of finned double-pass solar collector", Energy Convers Manage, November 75, 2013, pp. 234-240.

[14] W. Yao, Z. Li, Y. Wang, F. Jiang, L. Hu, "Evaluation of global solar radiation models for Shanghai, China", Energy Convers Manage, Augest 84, 2014, pp. 597-612.

[15] A. Teke, H.B. Y1ldırı, "Estimating the monthly global solar radiation for Eastern Mediterranean Region”, Energy Convers Manage, November 87, 2014, pp. 628-635.

[16] C. Stanciu, D. Stanciu, "Optimum tilt angle for flat plate collectors all over the World-A declination dependence formula and comparisons of three solar radiation models", Energy Convers Manage, May 81, 2014, pp. 133-143.

[17] B.Y.H. Liu, R.C. Jordan, "The interrelationship and characteristic distribution of direct, diffuse and total solar radiation", Solar Energy, July 4-3, 1960, pp. 1-19.

[18] R.C. Temps, K.L. Coulson, "Solar Radiation Incident upon Slopes of Different Orientations", Solar Energy, 19-2, 1977, pp. 179-184,

[19] M. Koussa, M. Haddadi, A. Malek, "Reconstitution des irradiations globale et diffuse en fonction de quelques paramètres météorologiques pour un ciel quelconque", Revue des Energies Renouvelables, 10-1, 2007, 75-92.

[20] T.M. Klucher, "Evaluation of models to Predict insolation on Tilted Surface", Solar Energy, 23-2, 1979, pp. 111-114.

[21] R. Perez, R. Stewart, C. Arbogast, R. Seals and J. Scott, “An Anisotropic Hourly Diffuse Model for Sloping Surfaces, 'Description, Performance Validation, Site Dependency Evaluation”, Solar Energy, 36-6, 1986, pp. 481-497.

[22] M. Koussa, A. Malek, M. Haddadi, "Validation de quelques modèles de reconstitution des éclairements dus au rayonnement solaire direct, diffus et global par ciel clair. Revue des Energies Renouvelables, December 9-4, 2006, pp. 307-332.

[23] P. Baltas, M. Tortoreli, P.E. Russell, "Evaluation of Power Output for Fixed and Step Tracking Photovoltaic Arrays', Solar Energy, 32-2, 1986, pp. 147-163.

[24] M. Mesri, I. Rougab, A. Cheknane, N.I. Bachari, "Estimation du rayonnement solaire au sol par des modèles semi-empiriques', Revue des Energies Renouvelables, September 15-3, 2012, pp. 451-463.

[25] M. Mesri, A. Cheknane, N. Bachari, I. Rougab, "Estimation du rayonnement mensuel global par jour par deux approches météorologiques en Algérie', Revue Canadienne de Physique, 89-12, 2011, pp. 1215-1218,

[26] V. Badescu, C.A. Gueymard, S. Cheval, C. Oprea, M. Baciu, A. Dumitrescu, et al, "Computing global and diffuse solar hourly irradiation on clear sky. Review and testing of 54 models', Renewable and Sustainable Energy Reviews, April 16-3, 2012, pp. 1636-1656. 